\title{
A democracia como valor de debate: a discussão entre Carlos Nelson Coutinho e Adelmo Genro Filho
}

\author{
Dédallo Neves ${ }^{1}$ \\ Recebido em março de 2020 \\ Aceito em junho de 2020
}

\section{RESUMO}

Em 1978, já no contexto da redemocratização e "abertura lenta, gradual e segura" anunciada pelo General Ernesto Geisel, muitos debates em torno da temática "democracia" ocorreram. A revista Encontros com a Civilização Brasileira (ECB) era um dos espaços disponíveis para pensar o que seria a democracia no Brasil após duas décadas de regime militar. A ECB circulou entre 1978 e 1982 e foi editada por Ênio Silveira e Moacyr Félix. Entre os quatro anos foram publicados 29 volumes. O trabalho em questão pretende elencar dois textos produzidos na ECB em torno da temática "democracia”. O primeiro de Carlos Nelson Coutinho, "A democracia como valor universal", onde o autor reflete sobre o vínculo existente entre democracia e socialismo e em que lugar há continuidades e rupturas entre a democracia de caráter burguês e a de caráter socialista. E o segundo de Adelmo Genro Filho, "A democracia como valor operário e popular", cujo objetivo é responder Coutinho. Genro Filho acusa o primeiro autor de certo reformismo na maneira de compreender a passagem de uma democracia a outra. Assim sendo, tendo como pano de fundo o debate entre os dois autores, suas posições e conceitos trazidos para teorizarem sobre o que seria democracia no socialismo, o artigo pretende resgatar os debates realizados na ECB no contexto da redemocratização brasileira.

Palavras-chave: Carlos Nelson Coutinho; Adelmo Genro Filho; Democracia; Encontros com a Civilização Brasileira.

\section{Democracy as debate value: the discussion between Carlos Nelson Coutinho and Adelmo Genro Filho}

\begin{abstract}
In 1978, in the context of Brazilian redemocratization and "slow, gradual and secure opening" announced by General Ernesto Geisel, many debates around the "democracy" theme took place. The periodical Encontros com a Civilização Brasileira (ECB) was one of the spaces available to think about what would be democracy in Brazil after two decades of military regime. ECB circulated between 1978 and 1982, it was edited by Ênio Silveira and Moacyr Félix. In those four years, 29 volumes were published. This article intends to list two texts produced at ECB around the "democracy" theme. The first one, by Carlos Nelson Coutinho, "A Democracia como valor universal" (loosely translated as "Democracy as a universal value"), where the author ponders on the link between democracy and socialism and in which places does exist continuities and ruptures between democracy of a bourgeois character and the one with socialist character. The second one by Adelmo Genro Filho, "A Democracia como valor operário e popular" (loosely translated as "Democracy as work and folk value"), whose aim is to answer Coutinho. Genro Filho accuses the first author of a certain reformism in his comprehension of the transition from one democracy to
\end{abstract}

1 Mestrando do Programa de Pós-Graduação em Sociologia da Universidade Federal do Paraná. E-mail: depaula.neves@hotmail.com. 
another. Therefore, taking as a background the debate between the two authors, their positions and concepts brought to theorize about what would be democracy in socialism, the article intends to rescue the debates held at ECB in the context of the Brazilian redemocratization.

Keywords: Carlos Nelson Coutinho; Adelmo Genro Filho; Democracy; Encontros com a Civilização Brasileira.

\section{Introdução}

A revista Encontros com a Civilização Brasileira (ECB) foi o último periódico, denominado "político-cultural”, editado por Ênio Silveira antes da venda de sua editora para o grupo DIFEL (Difusão Europeia do Livro), em 1982, mesmo ano em que a ECB deixou de circular.

Foram publicados 29 volumes entre 1978 e 1982, reunindo um grupo de intelectuais e uma variedade de assuntos com o propósito de "intensificar" e "colaborar" com o debate acerca das "liberdades democráticas" (SILVEIRA, 1978, pp. 7-8), de acordo com o editorial do número 1 da revista.

Buscava-se reconstruir, após anos de ditadura, o ambiente de debates e discussões ocorridos na RCB. "Em linhas gerais, como se pode ver, a coleção Encontros com a Civilização Brasileira mantém - e amplia - a linha de conduta intelectual que, de 1964 a 1968, cercou de tanto apreço a Revista Civilização Brasileira" (SILVEIRA, 1978, p. 8). De maneira geral, o que Vieira (1998) chamou de "Grupo Civilização" manteve-se na nova revista.

A ECB, segundo Ênio Silveira, recebeu editorialmente um caráter mais "profissional”, mas atribui a sua recepção menos calorosa do que teve a sua antecessora

\footnotetext{
2 "A RCB surge com seu primeiro número em março de 1965, exato um ano após o golpe militar, e durante toda sua existência jamais sofreu qualquer espécie de intervenção editorial ou mesmo repreensão por parte dos órgãos censores do governo militar. [...] A RCB teve grande importância na rearticulação de diversas correntes intelectuais atuantes do pré-64, dispostas também a fazer frente ao regime golpista" (CZAJKA, 2005, p. 9-10). Czajka também destaca que a edição da RCB entre 1965 e 1968 dá-se no mesmo período no qual se registra a produção mais intensa da própria editora. Os chamados "tempos de ouro" da Civilização Brasileira refletem justamente essa dupla condição; revela a tensão que situa a RCB tanto como um espaço crítico e reflexivo das esquerdas desagregadas pelo regime militar instaurado em 1964, quanto um sucesso editorial no vigor da ditadura militar" (CZAJKA, 2005, p. 12).
} 
a uma identidade ideológica menos nítida (VIEIRA, 1998). Entretanto, Couto (2012) em seu estudo sobre a revista concluiu:

Ambas foram heteróclitas em termos de princípios e concepções de mundo. Hão de ter sido diversas, claro, mas não a ponto de suas variações ideológicas se terem feito notar de modo tão contundente e comprometedor por seus leitores. Absolutamente, não se mostra satisfatória a atribuição da menor repercussão de Encontros à sua suspeita indefinição ideológica (COUTO, 2012, p. 356).

Um dos caminhos a identificar essa mesma linha condutora pode ser seguido na comparação, como propõe Couto (2012), entre os dois primeiros editoriais: "Princípios e propósitos" (1965) e "Por quê e para quê" (1978), onde Silveira reafirma o não-sectarismo das revistas.

Quaisquer que tenham sido as diferenças ou semelhanças entre as duas coleções, o argumento baseado apenas na identidade ideológica, como acontece usualmente, parece insuficiente para prover uma interpretação mais sólida, particularmente no que tem a ver com o problema da recepção. Isolado, resiste muito pouco à análise crítica (COUTO, 2012, p. 358).

Apesar de ambas as revistas circularem sob o mesmo regime, mesmos atores, mesmo país, as circunstâncias eram diferentes. Enquanto a RCB apresentou-se no começo da ditadura, a ECB surge num cenário de esgotamento, quase superação, da mesma. Isso abre novas brechas para novas discussões. A questão democrática é ressignificada e ganha fundamental importância. A "luta" na ECB não era mais, ou somente, a importância do regime democrático, mas qual regime democrático e em que circunstâncias. Isso foi observado por Benetti (2014) num levantamento preliminar em que buscou nos títulos a palavra "democracia” e a correspondência se deu em 18 artigos. O que não significa que apenas nesses o tema foi abordado, ele aparece em outros, tangenciando a discussão ou como tema central.

Nesse sentido, a questão democrática - que nesse momento começa a se tornar uma linguagem dominante em quase todas as variantes das esquerdas brasileiras - divide espaço com a retomada da reflexão sobre a questão nacional. A "democracia" aparece no título de 18 artigos publicados em ECB, 12 dos quais escritos por brasileiros, além de ser o tema principal de alguns outros. Na maioria deles, é da democracia política e representativa de que se está falando, embora a 
maior parte dos autores sustente a necessidade de se conjugá-la com formas diretas de representação das classes trabalhadoras (BENETTI, 2014, p. 17).

Debates importantes sobre a questão democrática foram pautados na revista, contribuindo para a intelligentsia brasileira aprofundar o tema e discutir alternativas sobre o que seria a democracia depois de um regime autoritário. Este espaço de atuação dos intelectuais ecoaria indiretamente na sociedade, seja através da ocupação de alguns deles em instâncias de poder, podendo citar o caso de Fernando Henrique Cardoso, que passa a fazer oposição no MDB e foi membro do Conselho Consultivo da ECB, seja na discussão do papel que o intelectual deveria desempenhar num regime democrático, como fez Florestan Fernandes no volume 14 ("Tarefa dos intelectuais na revolução democrática"). Ou ainda questionando a própria democracia, como realizado por João Almino (volume 19), em "A ideologia autoritária no discurso democrático". Portanto, há aqui um florescimento crescente na discussão sobre democracia, dialogando inclusive com o momento de redemocratização - Miguel Arraes no último volume da ECB publicou "Crise da democracia e abertura no Brasil". Como corolário, a importância da ECB ultrapassa o seu diálogo na e com a intelectualidade brasileira e alcança um diálogo amplo com a democracia.

Tendo isto em vista, o artigo pretende resgatar uma das discussões realizadas na revista, cuja contribuição para pensar a democracia num contexto socialista e brasileiro foi fundamental e um tanto polêmica. Carlos Nelson Coutinho escrevera para o volume 9 (março de 1979) o artigo "A democracia como valor universal”, cujo desenvolvimento faremos no tópico posterior. No volume 17 (novembro de 1979), Adelmo Genro Filho responde com o texto "A democracia como valor operário e popular", trazendo na gravata “(Resposta a Carlos Nelson Coutinho)", ou seja, o objetivo deste autor era justamente polemizar com o primeiro.

Este resgate serve a uma percepção parcial da dissertação em desenvolvimento sobre como o pensamento social brasileiro de matriz comunista, reduzido a ambos os autores, compreendia e manejava o conceito de democracia no período de redemocratização, temos neste artigo a democracia como valor de debate. 


\section{A tese de Coutinho}

Antes de adentrarmos a polêmica, faremos uma explanação das ideias de Coutinho para, adiante, podermos traçar as críticas de Genro Filho já devidamente contextualizadas e não haver, desta maneira, necessidade de repetições. Portanto, as críticas de Genro Filho serão apresentadas já com o debate mais teórico no que tange "democracia e socialismo".

Carlos Nelson Coutinho começa seu texto a dizer que o "vínculo entre socialismo e democracia marcou desde o início o processo de formação do pensamento marxista" (1979, p. 33). Relembra que o debate do valor universal da democracia está presente entre revisionistas e ortodoxos e em nomes como Rosa Luxemburgo, Lênin e Trótski. O autor classifica a associação de democracia política como uma forma de dominação burguesa equivocada, isto porque há um caráter mecânico entre os dois conceitos - "democracia política" e "dominação burguesa" - a partir de uma falsa interpretação da teoria marxista de Estado. No contexto brasileiro, de acordo com o autor, implicaria outro problema: não é possível pensar "uma luta imediata pelo socialismo" (Ibidem, p. 35) sem a "criação dos pressupostos políticos, econômicos e ideológicos que tornarão possível o estabelecimento e a consolidação do socialismo em nosso país" (Idem). Logo, apesar de negar o caráter mecânico entre democracia e dominação burguesa, o autor acredita que alguns "pressupostos" são necessários para o estabelecimento do socialismo, ou seja, é preciso haver um antes do outro.

Coutinho começa a parte um do artigo ("Algumas questões de princípio sobre o vínculo entre socialismo e democracia política"), a que discute fundamentalmente o que é a democracia como valor universal numa concepção marxista, a lembrar que para Lênin o substantivo democracia sempre aparece adjetivado, logo, uma democracia não pode ser "pura"; ela é burguesa ou proletária. Trocando em miúdos, não há "regime estatal sem conteúdo de classe determinado, sem que uma classe fundamental no modo de produção determinante exerça através desse regime (não importa por meio de quantas mediações) sua dominação sobre o conjunto da sociedade" (Idem).

A segunda defesa da universalidade da democracia, após dizer que não é possível estabelecer mecanicamente democracia com dominação burguesa, dá-se a partir de uma 
referência a Marx sobre Homero e sua universalidade à revelia do desaparecimento da sociedade grega 3 . O autor cogita que tal pensamento dispõe de um "alcance metodológico geral" (Ibidem, p. 36), o que permite tirar determinadas conclusões a respeito da democracia:

Nem objetivamente, com o desparecimento da sociedade burguesa que lhes serviu de gênese, nem subjetivamente, para as forças empenhadas nesse desaparecimento, perdem seu valor universal inúmeras objetivações ou formas de relacionamento social que compõem o arcabouço institucional da democracia política (Idem).

A democracia política na perspectiva de Coutinho é um valor estratégico permanente, pois permite consolidar uma nova sociedade a partir do aprofundamento de características da "velha", ou seja, a sociedade de caráter socialista. Porém, ressalta, isto nada tem a ver com uma continuação da democracia liberal do século XVIII aos moldes de Locke e Montesquieu; e sim com uma criação e mudança de função de novos institutos políticos que não existem ou se apresentam apenas embrionariamente na democracia liberal clássica (Ibidem). Não é dito textualmente, mas entende-se que o autor sugere alguma dialética, no sentido de aprofundar, criar e superar, desta forma escaparia das críticas de que o socialismo estaria sujeito à ação do tempo e de uma teleologia aristotélica. Daí, o valor da democracia ser estratégico e permanente, ou seja, universal. Por isso, o autor diz que a democracia não é um "simples princípio tático" (Ibidem, p. 37). O diálogo realizado por Coutinho nesta parte é com o Marx de "A guerra civil na França”, que naquela ocasião afirmara que o proletariado não poderia simplesmente se apropriar da "velha máquina estatal", era preciso destruí-la. "A classe operária não pode simplesmente se apossar da maquinaria estatal tal como ela se apresenta e dela servir-se para seus próprios objetivos. O instrumento político de sua escravização não pode servir como o instrumento político de sua emancipação" (MARX,

\footnotetext{
3 Embora não haja a referência de Coutinho sobre a passagem citada, em 1992 ele publica "Democracia e Socialismo" onde revisita suas argumentações do artigo aqui analisado e cita a passagem de Homero em Marx com a referência da seguinte obra: Marx, K. "Introdução para a crítica da economia política. São Paulo, Abril Cultural (Col. "Os Pensadores"), v. XXXV, 1974, p. 131. (COUTINHO, C. N. Democracia e Socialismo: questões de princípios e contexto brasileiro. Polêmicas do Nosso Tempo v.51. São Paulo: Cortez. 1992, p. 18).
} 
2011a, p. 169). O autor brasileiro argumenta que a metáfora de destruir o Estado foi entendida muitas vezes de modo bastante literal, o que levaria à associação mecânica entre democracia política e dominação burguesa. É preciso, de acordo com Coutinho, criar novas formas no seio do capitalismo, num processo onde o novo nasce no seio do velho até que este seja extinguido, assim como o a burguesia nasceu no seio do feudalismo, a sociedade socialista nasceria no seio da burguesa. Engels, na Introdução de 1891 à obra de Marx, salienta:

Desde o primeiro momento, a Comuna [de Paris] teve de reconhecer que a classe
trabalhadora, uma vez no poder, não podia continuar a operar com a velha
máquina estatal; que essa classe trabalhadora, para não tornar a perder o poder
que acabara de conquistar, tinha de, por um lado, eliminar a velha maquinaria
opressora até então usada contra ela, enquanto, por outro lado, tinha de
proteger-se de seus próprios delegados e funcionários, declarando-os sem
qualquer exceção, como substituíveis a qualquer momento (ENGELS, 2011, pp.
195-196).

Outro tópico que o autor considera importante tange a alienação política e a necessidade de superá-la como conditio sine qua non para que o Estado não fique isolado da sociedade.

\begin{abstract}
A superação da alienação econômica é condição necessária mas não suficiente para a realização do humanismo socialista: essa realização implica também a superação da alienação política [...] A superação da alienação política pressupõe o fim do "isolamento" do Estado, sua progressiva reabsorção pela sociedade que o produziu e da qual ele se alienou; ora, isso só se tornará possível através de uma crescente articulação entre os organismos populares de democracia direta e os mecanismos "tradicionais" de representação indireta (partidos, parlamentos etc.)" (COUTINHO, 1979, p. 38).
\end{abstract}

Para Coutinho, essa articulação gerará uma "síntese política” dos vários sujeitos coletivos, impedindo que a sociedade civil seja atomizada pela dominação burguesa.

Konder (2009) aborda a questão a partir do "apoliticismo", o qual seria uma consequência da alienação política. Esta possibilitou o surgimento da ideia de que o “indivíduo privado" poderia abandonar-se como "cidadão", ou seja, das suas práticas políticas públicas. O apoliticismo, além de "impedir que as classes e camadas da população excluídas do exercício do poder tomem consciência das suas potencialidades políticas", faz com que o "fazer política” torne-se mais uma especialização entre tantas 
na sociedade em que o trabalho é dividido (KONDER, 2009, p. 186). Coutinho acompanha, de certa maneira, as considerações de Konder ao dizer que o socialismo "não elimina apenas a apropriação privada dos frutos do trabalho coletivo", mas também “a apropriação privada dos mecanismos de dominação e de direção da sociedade como um todo" (COUTINHO, 1979, p. 38); por isso, para o autor, o socialismo não pode se fazer por intermédio de uma nova burocracia, cujo governo dar-se-ia de cima para baixo, e lembra dos ensinamentos de Marx em que a libertação do proletariado deve ser obra do próprio proletariado.

\footnotetext{
Nessa democracia de massas, a dialética do pluralismo - a autonomia dos sujeitos políticos coletivos - não anula, antes impõe, a busca constante da unidade política, a ser construída de baixo para cima, através da obtenção do consenso majoritário; e essa unidade democraticamente conquistada será o veículo de expressão da hegemonia dos trabalhadores (Ibidem, p. 40).
}

Ao se encaminhar já para o final da primeira parte do artigo, Coutinho faz uma síntese, num sentido dialético, do que seria o que ele chama "democracia de massas", contrapondo com a abstração liberal, que mistifica e oculta a hegemonia, e o totalitarismo, que reprime a pluralidade e "absolutiza a dominação", "a democracia de massas funda sua especificidade na articulação do pluralismo com a hegemonia, na luta pela unidade na diversidade dos sujeitos políticos coletivos autônomos" (Idem [itálico no original]). E termina com uma citação que "denuncia”, em certa forma, a sua perspectiva de preservação de determinadas características da democracia burguesa, mostrando-se fiel ao seu texto e apresentando-se como um teórico que não pensa a obra de Marx mecanicamente, como dito acima sobre a destruição do Estado: "Podemos concluir esse rápido esboço afirmando que a relação da democracia socialista com a democracia liberal é uma relação de superação dialética (Aufhenbung): a primeira elimina, conserva e eleva a nível superior as conquistas da segunda” (Idem [itálico original]).

\section{A antítese de Genro Filho}


A resposta de Genro Filho não acompanha ipsis litteris a sistematização de Coutinho. Há uma mescla entre a primeira e a segunda parte do artigo. A segunda parte, cuja explanação não realizamos na parte anterior, aborda "O caso brasileiro: a renovação democrática como alternativa à 'via prussiana”. Consideramos, para efeito de construção de texto, fazer o diálogo entre os autores junto das referidas críticas de Genro Filho. A questão "teórica” da democracia como valor universal foi posta. Genro Filho fará suas considerações para mostrar o "valor operário e popular" tomando muitas vezes o caso brasileiro como exemplo.

Posto isto, a nossa abordagem nesta parte do artigo mesclará as considerações de Genro Filho sobre o artigo de Coutinho com um aporte teórico sobre democracia e socialismo. Autores como Lênin, Kautsky, Rosa Luxemburgo e o próprio Marx e outros aparecerão para dialogar nesta polêmica.

Adelmo Genro Filho inicia sua resposta a Coutinho propondo um novo título, pois a expressão valor universal para o autor é tipicamente liberal, ou seja, para Genro Filho na Coutinho estabelece mecanicamente a relação entre universalidade da democracia e dominação burguesa.

\footnotetext{
Os trabalhadores e as demais classes populares igualmente não estão interessados na permanência das "regras do jogo" da democracia formal. Estas, são apenas aspectos das reivindicações potencializadas objetivamente pela estrutura econômica existente [...] Noutras palavras, nenhuma força social atualmente no Brasil tem interesse numa estabilidade democrático-liberal como dimensão estratégica [...] Portanto, as palavras-de-ordem democrático-liberais não representam um "momento" da luta política em nosso País, nem uma etapa a ser cumprida. Mas não podem ser classificadas de "táticas" ou "instrumentais" por motivos diferentes daqueles indicados por Coutinho, que assume uma postura ético-metafísica ao opor "democracia" (para ele um valor universal) e "tática política" (um mero instrumento para alcançar um fim que lhe é absolutamente exterior) (GENRO FILHO, 1979, pp. 197-198).
}

Não há possibilidade de a democracia formal ser uma tática ou valor permanente (universal) porque o marxismo propõe um novo conteúdo democrático. Logo, no lugar da adjetivação proposta por Coutinho, cuja referência vem de Lênin, Genro Filho diz que são dois substantivos diferentes, a essência que se adjetiva, colocala como valor universal impede a ruptura como transformação revolucionária. A diferença da democracia como valor universal para aquela com valor operário está na 
qualidade. Há um salto qualitativo no teor democrático, e também quantitativo no sentido de quem comporá esta democracia. "Há um valor - que não é liberal nem burguês - que pode ser indicado a priori como fundamento da democracia socialista, como antídoto do burocratismo: a mobilização constante da classe operária e demais camadas populares no exercício direto do poder" (Ibidem, p. 202). Rosa Luxemburgo ao discursar na fundação do Partido Comunista da Alemanha, em janeiro de 1919, afirmara que a "massa" aprende a exercer o poder, exercendo-o ${ }^{4}$. Esta crítica de Genro Filho também serviria para responder um ponto convenientemente destacado por Coutinho, em que este diz que o "golpismo de esquerda" - cuja marca está presente no pensamento e ação política no Brasil, segundo o autor - é um equívoco, pois se confunde com a maneira conservadora de se fazer e pensar política, a saber: "pelo alto", o que marcara os processos da "via prussiana" brasileira, por isso Coutinho afirma ser preciso a "socialização da política".

Embora, Coutinho encerre seu pensamento com uma proposta dialética (“elimina, conserva e eleva a nível superior”), Genro Filho não se convence e afirma que tal abordagem é de um caráter simplista e "torna-se, na prática, reformista” (Ibidem, p. 198). O que identificamos aqui é uma discussão que Lênin já realizara em polêmica com Kautsky e Vandervelde, onde afirma que ambos confundem dialética com ecletismo e explica:

\footnotetext{
A dialética nega as verdades absolutas, explicando a sucessão dos contrários e o significado das crises na história. O eclético não quer afirmações "demasiado absolutas", para introduzir o seu desejo pequeno-burguês e filisteu de substituir a revolução pelos 'graus transitórios" [...] A dialética é concreta e revolucionária, distingue a 'transição' da ditadura duma classe para a ditadura de outra classe, da 'transição' do Estado proletário democrático para o não-Estado ('extinção do Estado'). O ecletismo e a sofística dos Kautsky e dos Vandervelde, para agradar a burguesia escamoteiam tudo que há de concreto e preciso na luta de classes (LÊNIN, 198ob, p. 74).
}

Segundo Salvadori (1982, p. 336), Kautsky abandona o caráter revolucionário da passagem da democracia burguesa para a proletária porque nenhuma ditadura -

4 Disponível em <https://www.marxists.org/italiano/luxembur/1919/1/discorso.htm>. Acesso: 25 de março de 2019 . 
referência à ditadura do proletariado - pode ser parâmetro para superação da democracia formal burguesa, para Kautsky não há socialismo sem democracia. $\mathrm{O}$ equívoco - e Lênin à época esclareceu e Genro Filho acompanha Lênin — é que o caráter da ditadura do proletariado não é stricto sensu, "A ditadura não significa necessariamente a supressão da democracia para a classe que exerce essa ditadura sobre as outras classes, mas significa necessariamente a supressão [...] da democracia para a classe sobre a qual ou contra a qual se exerce a ditadura” (LÊNIN, 198ob, pp. 9-10).

O que poderia parecer secundário, torna-se central para a discussão entre os autores brasileiros, pois assim como Kautsky abandona a categoria de revolução para se dar a passagem de uma sociedade para a outra e se apega a formas de um Estado democrático moderno, ou seja, burguês (parlamento, com o princípio representativo, sufrágio universal, pluralidade de partidos), Coutinho também se aproxima desta ideia ao estabelecer passos ou etapas; ao final do seu artigo explana da seguinte forma:

Em primeiro lugar, lógica e cronologicamente, trata-se de primeiro conquistar e
depois consolidar um regime de liberdades fundamentais, para o que se torna
necessária uma unidade com todas as forças interessadas nessa conquista e
permanência das "regras do jogo" a serem implantadas por uma Assembleia
Constituinte dotada de legitimidade. E, em segundo lugar, trata-se de construir
as alianças necessárias para aprofundar a democracia no sentido de uma
democracia organizada de massas, com crescente participação popular
(COUTINHO, 1979, p. 45).

Genro Filho diz haver em Coutinho uma "tendência" a substituir o conceito leninista de revolução pelo "conceito de luta pela hegemonia enquanto processo contínuo", isto levar-lhe-ia a não romper com a democracia burguesa e sim dar continuidade, daí torna-se justificada a acusação de Genro Filho, citada acima, do reformismo de Coutinho. "Ao invés de privilegiar a ruptura da democracia burguesa em relação ao socialismo - em função da mudança radical de seu conteúdo - Coutinho privilegia a continuidade" (GENRO FILHO, 1979, p. 200). Na verdade, o conceito que Coutinho usa, de fato, para que haja um processo de renovação democrática "de baixo para cima” e uma ampliação e consolidação de conquistas e novos sujeitos políticos, é o 
de "guerra de posição" 5 , de origem gramsciana. Não obstante, a crítica de Genro Filho ainda sustenta-se, pois podemos observar em Coutinho "a permanência das 'regras do jogo' a serem implantadas por uma Assembleia Constituinte”. Embora Lênin tenha afirmado que não é condição imprescindível a supressão de voto da burguesia e que fora uma característica particular da Revolução Russa, também concluiu que caso a Assembleia Constituinte seja “convocada segundo listas dos partidos existentes antes da revolução proletária e camponesa, numa situação de domínio da burguesia, [ela] entra inevitavelmente em conflito com a vontade e os interesses das classes trabalhadoras e exploradas" (LÊNIN, 1980a, p. 433). Como Coutinho pretende uma alternativa à "via prussiana”, a Assembleia Constituinte com partidos burgueses parece reforçar, como reforçou, vide a história recente da redemocratização, características que o autor pretendia superar, como exemplo podemos citar um distanciamento e uma especialização da política. Por isso, Genro Filho é incisivo na crítica:

\begin{abstract}
A revolução burguesa já ocorreu no Brasil de forma completa, paralela mesmo ao processo de internacionalização da economia. Não podemos, portanto, limitar as tarefas da luta operária pelos critérios do liberalismo emedebista: Estado de Direito, eleições livres, liberdades sindicais e Assembleia Constituinte (GENRO FILHO, 1979, p. 200).
\end{abstract}

Lênin também destacara na Tese 3 - do texto "Teses sobre a Assembleia Constituinte" - que a composição de uma assembleia não necessariamente dará forma democrática a qualquer governo; inclusive destaca que a república dos Sovietes - com deputados operários, soldados e camponeses - era uma forma mais elevada de democracia do que a de caráter burguês (com Assembleia Constituinte), e dizia ser "a única forma capaz de assegurar a passagem menos dolorosa para o socialismo" (LÊNIN, 1980a, p. 431).

Logo, ao privilegiar a continuidade e não o rompimento a partir da revolução, Coutinho utiliza-se da tese socialdemocrata, de acordo com Genro Filho, diferenciando

5 "A riqueza polissêmica do conceito de guerra de posição é significativa do método gramsciano: ela tem um valor descritivo e gnosiológico e registra a transformação da arte militar aplicando-a à ciência política" (CICCARELLI, 2017, p. 358). A guerra de posição permite a "realização de um aparelho hegemônico, enquanto cria um novo terreno ideológico, determina uma reforma das consciências e dos métodos de conhecimento, é um fato de conhecimento, um fato filosófico" (GRAMSCI, 1999, p. 320). 
estruturas econômicas de políticas: "Sem pôr nem tirar, é a conhecida tese socialdemocrata: capitalismo e socialismo são estruturas econômicas, enquanto que democracia e ditadura são sistemas políticos" (GENRO FILHO, 1979, p. 201). Tal tese endossa interpretações que radicalizadas apontarão para afirmações como o comunismo soviético e o nazismo alemão serem sistemas essencialmente idênticos, como fez Hannah Arendt em Origens do totalitarismo ou que o comunismo seria a "revolução vermelha" enquanto o fascismo a "revolução marrom”, como fez Schoenbaum citado por Konder (1979, p. 76).

É importante salientar a contribuição da própria tradição marxista para esta separação entre o econômico e o político, e como não é possível encontrar esta ambivalência na obra marxiana, cujo pressuposto é exatamente o contrário, isto é, a vinculação entre economia e política como a face de uma mesma moeda. Porém, muito se debateu sobre base e superestrutura e não foram poucos os que definiram a base (economia) como determinante da superestrutura (política, relações jurídicas etc.), Ellen Wood esclarece:

\footnotetext{
A economia política burguesa, de acordo com Marx, universaliza as relações de produção quando analisa a produção abstraindo suas determinações sociais específicas - relações sociais, modos de propriedade e dominação, formas políticas ou jurídicas específicas. Isso não quer dizer que a "base" econômica se reflita em certas instituições "superestruturais" e por elas seja mantida, mas que a base produtiva em si existe sob o aspecto de formas políticas, sociais e jurídicas - em particular, formas de propriedade e dominação (WOOD, 2006, p. 29).
}

Por se tratar de um tema tão polêmico, consideramos relevante insistir na explicação: “o modo de produção não existe em oposição aos 'fatores sociais', e que a inovação radical de Marx em relação à economia política burguesa foi precisamente a definição do modo de produção e das próprias leis econômicas em termos de 'fatores sociais"” (Ibidem, p. 31).

Por fim, Genro Filho encerra seu artigo a dizer que "socialismo" com “democracia política” (isto é, burguesa):

é uma postura teórico-metodológica por demais conhecida na história das lutas operárias, que não faz avançar um centímetro sequer as questões reais do exercício de poder no socialismo. Ao contrário, elide o problema da verdadeira e 
original democracia operária e popular por construir. Portanto, a perspectiva da análise marxista coloca exatamente o problema da 'democracia como valor operário e popular' e não como 'Valor Universal' (GENRO FILHO, 1979, p. 202).

\section{Considerações finais}

À época da produção do texto de Coutinho, o Brasil sinalizava para a democracia. $\mathrm{O}$ regime militar depois de quase vinte anos saturava-se. O milagre econômico de Médici já tinha passado e a inflação dava as caras descontentando a classe média. Em 1979 surgiu o partido que viria a substituir o que outrora fora o PCB; o PT, fundado no sindicalismo, abriu espaço para que intelectuais compusessem o quadro partidário, entre eles esteve Carlos Nelson Coutinho, cujas divergências levaram-no ao PSOL anos mais tarde. Coutinho compôs uma ala do marxismo brasileiro cujas influências beberam na fonte do que ficou conhecido como eurocomunismo. Foi um dos responsáveis por introduzir Gramsci no debate brasileiro, ao lado de nomes como Leandro Konder, Michel Löwy e Otto Maria Carpeaux. O que aparentemente é uma biografia, revela traços que se expressaram na crítica de Genro Filho. Coutinho mobiliza categorias gramscianas para pensar democracia e "abandona" o conceito leninista de revolução, o que mostraria por um lado suas influências e abordagens e, por outro, carências brasileiras da época. Por isso, o autor pensava na garantia de liberdades fundamentais para aprofundar a democracia de massas, socialista. O momento de redemocratização exigia. Logo, o PT caiu como uma luva, uma vez que, desde o princípio, não era um partido revolucionário e socialista, mais identificado com a causa trabalhista. No entanto, o contexto histórico não fora suficiente para escapar das críticas de Genro Filho. Ironicamente, Genro Filho - cuja crítica à democracia burguesa foi voraz, denunciara o reformismo de Coutinho e exigira uma democracia proletária, com uma superação radical da democracia burguesa, criticando, inclusive, o "emedebismo" - compunha a Câmara de Vereadores de Santa Maria, no Rio Grande Sul, pelo próprio MDB. Usar de tais aspectos biográficos de ambos para legitimar uma crítica ou outra soaria desleal, a principal questão a ser destacada neste debate mora na tensão existente entre a mobilização de categorias gramscianas e o eurocomunismo de Coutinho e a 
“exigência” de Genro Filho do uso da revolução como motor para uma democracia de valor operário.

Não temos a pretensão aqui de optar entre um e outro. Nosso objetivo era uma primeira tentativa de observar os debates existentes na Encontros com a Civilização Brasileira e como eles se relacionam de certa maneira com o contexto da época.

Para além dos dois artigos, há mais dezesseis cuja temática central indicada pelo título abordam questões democráticas, esta, no entanto, talvez tenha sido a mais polêmica delas, o que nos obriga, entre a tese de Coutinho e a antítese de Genro Filho, a uma síntese. Julgamos que o melhor caminho seja retornar aos escritos marxianos.

Há no próprio Marx uma diferenciação num curto espaço de tempo de como ele compreende democracia. Em 1843, na Crítica da filosofia do direito de Hegel, o autor afirma a "verdadeira democracia", no sentido rousseauniano (ENDERLE, 2013, p. 8). Marx, no entanto, no final do mesmo ano preparou uma introdução à Crítica, publicada em 1844 nos Anais Franco-Alemães, neste espaço ele já trazia o conceito de "democracia acabada" (vollendete Demokratie), acontece em seu pensamento "uma transição do liberalismo burguês ao tema da 'emancipação humana' (isto é, do comunismo), enquanto a democracia passa a ser identificada com a 'emancipação política' (ENDERLE, 2013, p. 8). Na “Introdução”, Marx convoca a necessidade de uma “revolução radical” para haver a autorrealização das pessoas na sociedade, o que ele discutiria em Sobre a questão judaica abordando os temas da emancipação humana e emancipação política.

Queremos colocar com essa breve explanação as possibilidades de entendimento no que tange a democracia seja como ferramenta para o socialismo, como quis Coutinho ou como "revolução radical" que se aproxima do pensamento de Genro Filho. Não cabe a nós nesta "síntese" apontar o destino da democracia no socialismo.

O debate entre ambos os autores elencado neste artigo é uma das formas de perceber discussões no âmbito do pensamento social brasileiro em seu contexto de redemocratização, e como ambos os intelectuais manejavam a categoria de democracia para pensar e propor uma sociedade que se "renovava” com a redemocratização. Como dito acima, para além destes dois artigos, há outros que naquele momento e naquele espaço (Encontros com a Civilização Brasileira) debatiam sobre o assunto. 


\section{Referências}

BENETTI, Pedro. "Encontros com a democracia: intelectuais e a transição no período 1978- 1982”. IX Encontro da ABCP: Pensamento político brasileiro. Brasília, 2014.

CICCARELLI, Roberto. “Guerra de posição”. In: LIGUORI, G.; PASQUALE, V. (Org.). Dicionário Gramsciano (1926-1937). São Paulo: Boitempo, 2017, p. 358-36o.

COUTINHO, Carlos Nelson. "A democracia como valor universal”. In: Encontros com a Civilização Brasileira, n.9, mar/1979, p. 33-47.

COUTINHO, Carlos Nelson. Democracia e Socialismo: questões de princípios e contexto brasileiro. Polêmicas do Nosso Tempo v.51. São Paulo: Cortez. 1992

COUTO, Cristiano P. P. “Encontros com a Civilização Brasileira (1978-1982): resistência cultural e prenúncio de uma nostalgia”. Dimensões, vol. 29, 2012, p. 351-373.

CZAJKA, Rodrigo. Páginas de resistência: intelectuais e cultura na Revista Civilização Brasileira. Campinas, 2005, 126p. Dissertação (Mestrado em Sociologia da Cultura) Departamento de Sociologia, Universidade Estadual de Campinas.

ENDERLE, R. "Apresentação". In: MARX, K. Crítica da filosofia do direito de Hegel. São Paulo: Boitempo, 2013. p. 17-32.

ENGELS, Friedrich. "Introdução à Guerra Civil na França, de Karl Marx (1891)". In: MARX, Karl. A guerra civil na França. São Paulo: Boitempo, 2011, p. 187-197.

GENRO FILHO, Adelmo. “A democracia como valor operário e popular”. In: Encontros com a Civilização Brasileira, n.17, nov/1979, p. 195-202.

GRAMSCI, Antonio. Cadernos do Cárcere. Vol. 1. Rio de Janeiro: Civilização Brasileira, 1999 .

KONDER, Leandro. Marxismo e alienação. São Paulo: Expressão Popular, 2009.

. Introdução ao fascismo. Rio de Janeiro: Graal, 1979.

LÊNIN, V.I. Obras escolhidas. Vol. 1. São Paulo: Alfa-Omega, 1986.

Obras escolhidas. Vol. 2. São Paulo: Alfa-Omega, 1980a.

Obras escolhidas. Vol. 3. São Paulo: Alfa-Omega, 198ob.

MARX, Karl. A guerra civil na França. São Paulo: Boitempo, $2011 a$. 
Grundrisse. São Paulo: Boitempo, 2011b.

SALVADORI, Massimo L. "Kautsky entre ortodoxia e revisionismo". In: Hobsbwam, Eric. História do Marxismo: o marxismo na época da Segunda Internacional. Vol. 2 (Primeira parte). Rio de Janeiro: Paz e Terra, 1982, p. 299-339.

SILVEIRA, Ênio. Por quê e Para quê. In: Encontros com a Civilização Brasileira, n.1, jul/1978.

VIEIRA, Luiz R. Consagrados e malditos: os intelectuais e a editora Civilização Brasileira. Brasília: Thesaurus, 1998.

WOOD, Ellen M. Democracia contra o capitalismo: a renovação do materialismo histórico. São Paulo: Boitempo, 2006. 